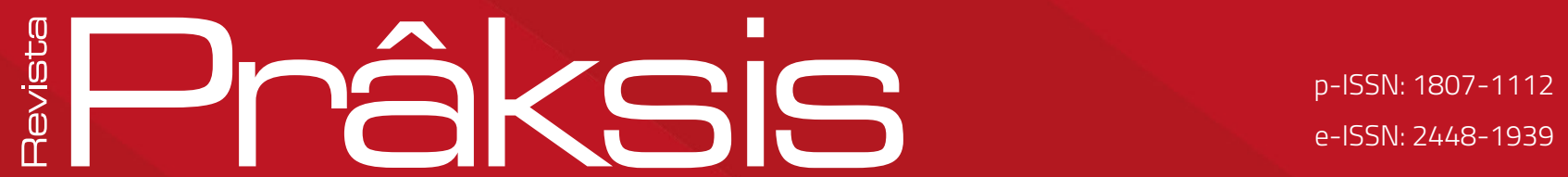

Recebido em: 25 de setembro de 2018 Aprovado em: 19 de janeiro de 2019 Sistema de Avaliação: Double Blind Review RPR |a. 16 | n. 2 |p. 184-208| mai./ago. 2019 DOI: https://doi.org/10.25112/rpr.v2i0.1910

\title{
HÁ DIFERENÇA? PROCESSOS DE CONSTITUIÇẤO DA IDENTIDADE PROFISSIONAL DE DOCENTES HOMOSSEXUAIS
}

\section{IS THERE ANY DIFFERENCE? PROCESSES OF CONSTITUTION OF PROFESSIONAL IDENTITY OF HOMOSEXUAL TEACHERS}

\section{Maria Cláudia Dal'Igna}

Doutora em Educação pela Universidade Federal do Rio Grande do Sul- UFRGS (Porto Alegre/Brasil). Professora na Universidade do Vale do Rio dos Sinos (São Leopoldo/Brasil).

E-mail: mcigna@unisinos.br

\section{Jonathan Vicente da Silva}

Mestrando em Educação pela Universidade do Vale do Rio dos Sinos (São Leopoldo/RS).

E-mail: jonathanvicente10@hotmail.com

\section{Miriã Zimmermann da Silva}

Doutoranda em Educação pela Universidade do Vale do Rio dos Sinos (São Leopoldo/RS).

E-mail: miriazimm@gmail.com 


\section{RESUMO}

Neste trabalho, são apresentados resultados de uma pesquisa de Trabalho de Conclusão de Curso em Pedagogia, que está articulada a um Projeto de Pesquisa mais abrangente, desenvolvido em um Programa de Pós-Graduação em Educação. Busca-se mapear, descrever e analisar os processos de constituição da profissionalidade de docentes homossexuais, operando com as ferramentas de gênero e sexualidade, entendendo que estas conformam a profissionalidade destes docentes. Como procedimento teórico-metodológico, para compor o material empírico da pesquisa, utilizou-se a entrevista-narrativa e, com base nos Estudos de Gênero, nos Estudos Queer e na Teoria Pós-Estruturalista, foram entrevistados quatro professores homens gays e uma professora mulher lésbica, em efetivo exercício docente, em escolas públicas e privadas da região do Vale do Rio dos Sinos, Rio Grande do Sul. A partir das análises, foi possível mostrar como gênero e sexualidade atravessam e dimensionam a docência homossexual, mais especificamente a profissionalidade. Embora estes professores e esta professora evidenciam, em suas narrativas, o quanto a docência homossexual é vista como algo que foge do centro, percebeu-se a possibilidade de deslocamento desta docência considerada ex-cêntrica, ou ainda, uma docência reprimida, para pensarmos em uma docência interpelada pelos discursos inclusivos. Com base na pesquisa, conclui-se que um ethos profissional inclusivo se forma na medida em que, ao (re)significarem as experiências, ao se relacionarem consigo mesmo e com os outros, ao se olharem no outro e se reconhecerem na diferença do outro, mobilizam outras formas de ser e exercer a docência.

Palauras-chave: Docência. Docência homossexual. Profissionalidade docente. Gênero e Sexualidade.

\section{ABSTRACT}

In this article the results of a research developed in a Graduation Course Work in Pedagogy are presented. This research is linked to a broader Research Project developed in a Post-Graduate Program in Education. The research seeks mapping, describing and analyzing the processes of constitution of homosexual teacher's, professionalism operating with gender and sexuality as tools, understanding that these tools conform the professionalism of these teachers. As a theoretical-methodological procedure the interview-narrative was used to compose the empirical material of the research. Based on the Gender Studies, the Queer Studies and the Post-Structuralist Theory were interviewed four male gay teachers and one female lesbian teacher, in effective teaching practice, in public and private schools in the Vale do Rio dos Sinos region, in Rio Grande do Sul. From the analyzes it was possible to show how gender and sexuality cross and size homosexual teaching, more specifically teacher's professionalism. Although these teachers show in their narratives how homosexual teaching is seen as something that escapes from the center it was noticed a possibility of displacement of this teaching considered eccentric, or even a repressed teaching, to think about a teaching interpellated by inclusive discourses. Based on the research it is concluded that an inclusive professional ethos is formed to the extent that teachers (re)signify their experiences, when they relate to themselves and to the others, when they look at themselves on the other and recognize themselves in the difference of the other, they mobilize other ways of being and practicing teaching.

Keywords: Teaching. Homosexual teaching. Teacher's professionalism. Gender and Sexuality. 


\section{INTRODUÇÃO}

Há diferença entre professores e professoras heterossexuais e homossexuais (gays e lésbicas)? Os modos como cada um e cada uma vive seus gêneros e suas sexualidades imprime marcas específicas em seu exercício docente? Há uma docência homossexual que se diferencie da docência heterossexual? Mobilizados por estas perguntas - e muitas outras - apresentamos, neste trabalho, resultados de uma pesquisa de Trabalho de Conclusão de Curso em Pedagogia, que está articulada a um Projeto de Pesquisa mais abrangente sobre Docência e Gênero, desenvolvido em um Programa de Pós-Graduação em Educação".

Apoiados nos Estudos de Gênero, nos Estudos Queer e na teoria Pós-Estruturalista, a pesquisa foi desenvolvida a partir da análise de narrativas de quatro homens professores gays e uma mulher professora lésbica, em efetivo exercício docente, em escolas públicas e privadas da região do Vale do Rio dos Sinos, Rio Grande do Sul. Neste texto temos por objetivo mapear, descrever e analisar os processos de constituição da profissionalidade de docentes homossexuais, operando com as ferramentas de gênero e sexualidade, entendendo que estas conformam a profissionalidade destes docentes.

0 presente trabalho está organizado em duas partes, a saber: na primeira, apresentamos uma breve revisão teórica dos conceitos que são importantes para a pesquisa, tais como: gênero, sexualidade e profissionalidade docente. Na segunda parte, realizamos a análise do material empírico, mostrando o processo de constituição de um modo de ser docente específico.

\section{GÊNERO, SEXUALIDADE E PROFISSIONALIDADE DOCENTE}

[...] Homens e mulheres certamente não são construídos apenas através de mecanismos de repressão ou censura, eles e elas se fazem, também, através de práticas e relações que instituem gestos, modos de ser e estar no mundo, formas de falar ou de agir, condutas e posturas apropriadas (e, usualmente, diversas). Os gêneros se produzem, portanto, nas relações de poder (LOURO, 2011, p. 45).

Iniciamos esta seção com uma citação em que Guacira Louro (2011) nos provoca a pensar que os gêneros são produzidos nas relações de poder. Apoiados nos estudos realizados por Michel Foucault acerca do poder, entendemos que poder não se restringe a força que uns exercem sobre outros, não está

\footnotetext{
${ }^{1}$ Trata-se da pesquisa "A produção de sentidos sobre afeto, amor e cuidado na formação inicial docente sob a perspectiva de gênero" (DAL'IGNA, 2017) à qual vincula-se o Trabalho de Conclusão: "Gênero, sexualidade e profissionalidade: uma análise das narrativas de docentes homossexuais" (2018).
} 
centralizado, a priori, em uma única pessoa, mas se estabelece nas relações. Foucault (1995), ao abordar as relações entre sujeito e poder, vai sugerir uma análise sobre o que ele chama de "uma nova economia das relações de poder" (FOUCAULT, 1995, p. 234), que "mais do que analisar o poder do ponto de vista de sua racionalidade interna, [...] consiste em analisar as relações de poder através do antagonismo das estratégias". (FOUCAULT, 1995, p. 234). 0 autor explica, ainda, que não basta afirmar que as relações de poder são lutas antiautoritárias, é preciso defini-las. Ao longo do texto Foucault (1995, p. 234-235) vai dizer que são: 1- Lutas "transversais" que não se limitam a um país; 2- Lutas que objetivam efeitos de poder enquanto tal; 3- Lutas imediatas, que "[...] criticam-se as instâncias de poder que thes são mais próximas, aquelas que exercem sua ação sobre os indivíduos. Elas não objetivam a 'inimigo mor', mas o inimigo imediato"; 4- Lutas que "questionam o estatuto do indivíduo: por um lado, afirmam o direito de ser diferente e enfatizam tudo aquilo que torna os indivíduos verdadeiramente individuais" mas que por outro lado, "atacam tudo aquilo que separa o indivíduo, que quebra sua relação com os outros [...]"; 5Lutas que se opõem aos efeitos de poder que estão relacionados com o saber, à competência, são "lutas contra os privilégios do saber", e 6- Lutas contemporâneas, que " [...] giram em torno da questão: quem somos nós? [...]".

Foucault (1995) entende, portanto, que as relações de poder além de "[...] força[r] o indivíduo a se voltar para si mesmo e o liga[r] à sua própria identidade de um modo coercivo" (FOUCAULT, 1995, p. 235), implica liberdade, opera sobre sujeitos livres, consiste em operar na condução das condutas, portanto, se estabelece num jogo de disputas.

Deste modo, retomando a ideia de Louro (2011), pode-se afirmar que as masculinidades, as feminilidades e as homossexualidades são constituídas através de práticas e relações de poder que instituem modos de ser e estar no mundo, definidos como mais ou menos adequados.

Definir gênero não é uma tarefa fácil, já que este foi e é alvo de diversos debates - um campo em disputa - que inicia pelos movimentos sociais, mais especificamente, pelo feminismo ao final do século XIX e no início do século XX, em países como a França e os Estados Unidos. Quando nos propomos a estudar gênero, o fazemos a partir de estudiosas como Joan Scott, Linda Nicholson, Guacira Louro e Dagmar Meyer. Retomaremos algumas de suas principais contribuições a fim de indicar como compreendemos e operamos com gênero nesse presente texto e em nossas pesquisas.

Joan Scott (1995, p. 3), autora do estudo traduzido para o português como "Gênero: uma categoria útil de análise histórica", mostra em seus estudos, que o termo gênero emerge dos movimentos feministas americanos que "queriam insistir no carácter fundamentalmente social das distinções baseadas no sexo". Segundo a autora 
[...] o gênero é igualmente utilizado para designar as relações sociais entre os sexos. 0 seu uso rejeita explicitamente as justificativas biológicas, como aquelas que encontram um dominador comum para várias formas de subordinação no fato de que as mulheres têm filhos e os homens têm uma força muscular superior. Gênero se torna, aliás, uma maneira de indicar as 'construções sociais' - a criação inteiramente social das idéias sobre os papeis próprios aos homens e às mulheres (SCOTT, 1995, p. 7).

Scott (1995) indica que esta discussão, instaurada pelas feministas anglo-saxãs, procurava abandonar a ideia de um determinismo biológico que expressões como "sexo" suscitavam, e defender a ideia de que "gênero" passava a indicar as construções sociais, culturais e históricas. Acerca deste mesmo movimento, Louro (2014, p. 22) afirma que não havia "[...] a pretensão de negar que o gênero se constitui com ou sobre corpos sexuados, ou seja, não é negada a biologia, mas enfatizada, deliberadamente, a construção histórica produzida sobre as características biológicas".

Linda Nicholson (2000) corrobora o que Scott (1995) nos apresenta. Autora do estudo traduzido no Brasil como "Interpretando o Gênero", a pesquisadora argumenta que o binarismo do termo "gênero", que é desenvolvido e usado em oposição a sexo, descreve o que é socialmente construído. Isto possibilita pensar o termo descolando-o do corpo e estabelecendo relação com a personalidade, com o comportamento. Por outro lado, o termo passa a ser usado, frequentemente, "como referência a qualquer construção social que tenha a ver com as distinções masculino/feminino, incluindo as construções que separam corpos femininos de corpos masculinos". (NICHOLSON, 2000, p. 53). A autora mostra, ainda, que, mesmo que a segunda concepção predomine nos discursos feministas, existe uma herança da primeira, em que o sexo vai ocupar um lugar que fica de fora da cultura e da história, enquadrando sempre a diferença masculino/feminino.

Baseada em Scott, Nicholson e outras feministas pós-estruturalistas, Guacira Louro, pesquisadora da Universidade Federal do Rio Grande do Sul e fundadora do Grupo de Estudos de Educação e Relações de Gênero (GEERGE), desenvolveu, em 1990, um importante estudo intitulado "Gênero, sexualidade e educação: uma perspectiva pós-estruturalista". Na obra, a autora apresenta com rigor teóricometodológico os conceitos e teorizações que compõem este campo e discute as implicações do uso dos conceitos de gênero e sexualidade para pensar as práticas educativas.

Dagmar Meyer, pesquisadora do GEERGE e uma das primeiras orientandas de Louro, apresenta uma análise muito relevante sobre as chamadas ondas do feminismo e as implicações teóricas e metodológicas do conceito de gênero para a Educação. Em seu estudo "Gênero e educação: teoria e política" (2011), Meyer descreve o movimento feminista no Brasil, mostrando que a primeira onda começou com a Proclamação da República, em 1890, e acabou quando o direito ao voto foi estendido às 
mulheres brasileiras, na constituição de 1934. A autora explica, também, que na virada do século XIX, no Ocidente, o movimento sufragista, reconhecido como a "primeira onda do feminismo" ganha visibilidade através das manifestações que eram realizadas contra a discriminação feminina. Estas manifestações, por sua vez, visavam que o direito ao voto fosse garantido às mulheres.

Ao final dos anos 1960, a chamada segunda onda vai se instaurar, com a intensificação de movimentos sociais em países como França, Estados Unidos e Inglaterra. Nestes países, diferentes grupos (intelectuais, estudantes, mulheres, negros, entre outros) mostravam-se inconformados com os arranjos sociais e políticos, bem como, com o vazio formalismo acadêmico, criando condições para o ressurgimento do movimento feminista que passou a expressar-se, nas palavras de Louro $(2014$, p. 16), "não apenas através de grupos de conscientização, marchas e protestos públicos, mas também através de livros, jornais e revistas".

Também, aqui no Brasil, a partir dos anos 1990, "militantes feministas participantes do mundo acadêmico vão trazer para o interior das universidades e escolas questões que as mobilizam, impregnando e 'contaminando' o seu fazer intelectual". (LOURO, 2014, p. 16). A partir deste movimento surgirá, então, a chamada terceira onda, dedicada aos "estudos da mulher" que objetivavam, segundo Louro (2014, p. 17) "tornar visível aquela que fora ocultada [...]. A segregação social e política a que as mulheres foram historicamente conduzidas tivera como consequência a sua ampla invisibilidade como sujeito - inclusive como sujeito da Ciência". A autora deixa evidente que, mesmo que as mulheres já tivessem conseguido romper com a concepção de um lugar que foi construído - social e cultural - como a priori de mulheres (cuidadora do lar, responsável pela família) e estas já ocupassem outros espaços de trabalho, ainda que suas atividades fossem controladas e estivessem sob supervisão de homens, as estudiosas feministas, através deste movimento, "iriam também demonstrar e denunciar a ausência feminina nas ciências, nas letras, nas artes". (LOURO, 2014, p. 17). Louro (2014, p. 18) demonstra que estes primeiros estudos constituíam-se em descrever as condições de vida, de trabalho das mulheres nos diversos espaços, consistindo em "estudos das áreas da Antropologia, Sociologia, Educação, Literatura, etc. [que] apontam ou comentam as desigualdades sociais, políticas, econômicas, jurídicas, denunciando a opressão e submetimento feminino". Estes primeiros estudos trarão as mulheres para o centro "[...] as quais eram usualmente apresentadas como exceção, a nota de rodapé, o desvio da regra masculina [...]" (LOURO, 2014, p. 19), o que marcou, significativamente, os Estudos Feministas, pois percebia-se aí o seu caráter político.

Neste período será "colocada sob suspeita a dicotomia produzida na segunda onda, de igualdade versus diferença". (ZANETTE, 2014, p. 19). Louro (2014, p. 20-21) indica que a compreensão de que 
há uma distinção biológica entre homens e mulheres e que seus papéis, portanto, são diferentes e complementares, adquiriu um "caráter de argumento final, irrecorrivel", servindo "para compreender - e justificar - a desigualdade social". A autora é categórica em seu posicionamento, ao afirmar que

É necessário demonstrar que não são propriamente as características sexuais, mas é a forma como essas características são representadas ou valorizadas, aquilo que se diz ou pensa sobre elas que vai construir, efetivamente, o que é feminino ou masculino em uma dada sociedade e em um dado momento histórico (LOURO, 2014, p. 21).

Nesta direção podemos afirmar que, para entender as relações entre homens e mulheres, é necessário observar além dos seus sexos. É preciso descrever e analisar tudo o que foi/é social, cultural e historicamente construído sobre os sexos. Há aí, um deslocamento importante na maneira de pesquisare operar com gênero e sexualidade, de modo que "ainda que os estudos continuem priorizando as análises sobre as mulheres, eles estarão agora, de forma muito mais explícita, referindo-se também aos homens". (LOURO, 2014, p. 22).

Louro (2014) e Meyer (2011), em seus estudos, indicam que não devemos reduzir ou simplificar o conceito de gênero em "papéis" - masculinos e femininos. Isto não significa negar que o gênero constituise com ou sobre corpos sexuados, como mencionado anteriormente. Conforme Meyer (2011, p. 16),

As abordagens feministas pós-estruturalistas se afastam daquelas vertentes que tratam o corpo como uma entidade biológica universal (apresentada como origem das diferenças entre homens e mulheres, ou como superfície sobre a qual a cultura opera para produzir desigualdades) para teorizá-lo como um construto sócio-cultural e lingüístico, produto e efeito de relações de poder.

Jeffrey Weeks (2015, p. 43) afirma que, nos dois últimos séculos, o "sexo" tem sido usado "como um termo descritivo para as diferenças anatômicas básicas, internas e externas ao corpo, que vemos como diferenciando homens e mulheres", e mesmo que estas distinções anatômicas sejam dadas desde o nascimento, "os significados a elas associados são altamente históricos e sociais".

A compreensão que assumimos sobre gênero e sexualidade, portanto, está fortemente relacionada com o "construcionismo social", que afirma que

[...] só podemos compreender as atitudes em relação ao corpo e à sexualidade em seu contexto histórico específico, explorando as condições historicamente variáveis que dão origem à importância atribuída à sexualidade num momento particular e apreendendo as várias relações de poder que modelam o que vem a ser visto como comportamento normal ou anormal, aceitável ou inaceitável. (WEEKS, 2015, p. 43). 
Compreender desta forma é ir contra um essencialismo biológico, sexual, "que tenta explicar as propriedades de um todo complexo por referência a uma suposta verdade ou essência interior". (WEEKS, 2015, p. 43).

Ainda, sobre o conceito de sexualidade, Foucault (2015, p. 115) afirma que

não se deve concebê-la como uma espécie de dado na natureza que o poder é tentado a pôr em xeque, ou como um domínio obscuro que o saber tentaria, pouco a pouco, desvelar. A sexualidade é o nome que se pode dar a um dispositivo histórico: não à realidade subterrânea que se apreende com dificuldade, mas à grande rede da superfície em que a estimulação dos corpos, a intenção dos conhecimentos, o reforço dos controles e das resistências encadeiam-se uns aos outros, segundo algumas grandes estratégias de saber e de poder.

Foucault (2015), ao propor-nos pensar que a sexualidade se estabelece nas relações de poder e saber, corrobora para questionarmos a visão essencialista que se tem sobre a sexualidade. Weeks $(2015$, p. 45$)$ vai mostrar que Foucault

acreditava que os argumentos essencialistas ignoravam o fato central sobre a sociedade moderna: de que a sexualidade era um 'aparato histórico' que tinha se desenvolvido como parte de uma rede complexa de regulação social que organizava e modelava ('policiava') os corpos e os comportamentos individuais.

Desta forma, podemos entender que "a sexualidade não pode agir como uma resistência ao poder porque está demasiadamente envolvida nos modos pelos quais o poder atua na sociedade moderna". (WEEKS, 2015, p. 45).

Pensando nas discussões sobre gênero e sexualidade e nas relações de poder que foram desenvolvidas até aqui, não temos como negar que os gêneros e as sexualidades se produzem, portanto, nas e pelas relações de poder. Tais relações de poder também são constituintes da identidade profissional de docentes e, no caso específico deste trabalho, de professores homossexuais, conforme a compreensão de que os sujeitos "se constituem de múltiplas e distintas identidades (de gênero, de raça, etnia, sexualidade etc.), na medida em que são interpelados a partir de diferentes situações, instituições ou agrupamentos sociais". (LOURO, 2015, p. 240).

Ao afirmar isto, nesta pesquisa, entendemos que a identidade não é essencial, fixa e imutável. Selma Pimenta (2008), acerca da constituição de uma identidade profissional docente, indica que a identidade é uma construção histórica e social. Deste modo podemos considerar que a própria profissão do professor "emerge em dado contexto e momento histórico, como resposta a necessidades que estão postas pelas sociedades, adquirindo estatuto de legalidade". (PIMENTA, 2008, p. 18). 
Assim, concluiremos esta seção indicando, também, a compreensão que temos acerca de um terceiro conceito - o da profissionalidade docente. Apoiando-nos nas ideias de Pimenta (2008) e Agostinho Monteiro (2015), procuramos refletir sobre a profissão docente, a profissionalidade e autorregulação. Como este trabalho volta-se, de modo especial, para a profissionalidade docente, focalizamos as discussões que Monteiro (2015) estabelece sobre profissão, profissionalização e profissionalidade.

Segundo Monteiro (2015), ao olhar para a etimologia da palavra profissão, pode-se apontar que esta "significa declaração de crença religiosa ou de convicções. Por exemplo: fazer uma 'profissão de fé', professar o 'ideário democrático'"'. (MONTEIRO, 2015, p. 25). 0 autor busca apoio nos estudos sociológicos sobre trabalho para mostrar a distinção anglo-saxônica entre profissão e ocupação. A partir de uma retomada teórica, histórica e social, Monteiro (2015, p. 14) dirá que as profissões se distinguem de outras ocupações por seguirem alguns atributos: 1) por desempenhar funções de grande responsabilidade; 2) por ter uma base teórica; 3) por aplicar seus saberes à resolução de problemas práticos; 4) porque estes saberes aplicados, são transmissíveis através de um ensino sistemático; 5) por auto organizar-se em associações e 6) por ter um ideal de serviço. Acerca da profissão, o autor segue dizendo que "seu conceito principal não é, pois, o de atributos profissionais, mas o de profissionalização, entendida como um processo através do qual a profissão é construída pelos que a exercem, coletivamente e como forma de realização pessoal". (MONTEIRO, 2015, p. 15).

Seguindo esta lógica, Monteiro (2015, p. 28) afirma que "as profissões distinguem-se pelo seu grau de profissionalidade". Profissionalidade, segundo Monteiro (2015, p. 38), seria "um processo coletivo e individual de construção de uma profissão e de aquisição de uma competência profissional", que pode ainda ser entendida sobre duas concepções: restrita e ampla. A primeira, qualificaria o que é profissional, e a segunda, seria o perfil global de uma profissão, "tudo o que distingue de outros grupos ocupacionais". (MONTEIRO, 2015, p. 29).

Ao olhar para a palavra profissionalidade percebemos o emprego do sufixo "idade", que designa modo de ser, qualidade, estado. Por profissionalidade docente, entendemos, concordando com as ideias de José Sacristán (1995, p. 65) "[o que] é específico na acção docente, isto é, o conjunto de comportamentos, conhecimentos, destrezas, atitudes e valores que constituem a especificidade de ser professor".

Com base nos conceitos de gênero, sexualidade e profissionalidade apresentados aqui, desenvolveremos, na seção seguinte, uma análise do processo de constituição da profissionalidade de docentes homossexuais. 


\section{ATRAVESSAMENTOS DE GÊNERO E SEXUALIDADE NA CONSTITUIÇÃO DA PROFISSIONALIDADE DOCENTE}

Para mapear, descrever e analisar os processos de constituição da profissionalidade de docentes homossexuais, operamos com as ferramentas de gênero e sexualidade, entendendo que estas que conformam a profissionalidade. Para tanto, utilizou-se a entrevista narrativa como procedimento metodológico, pois concordamos com Sandra dos Santos Andrade (2014) quando ela explica que através deste tipo de entrevista "é possível reconstruir as significações que os sujeitos atribuem ao seu processo de escolarização [de profissionalização e profissionalidade], pois falam de si, reinventando o passado, ressignificando o presente e o vivido para narrar a si mesmo". (ANDRADE, 2014, p. 176). Segundo a autora, ao narrar, falamos de nós, reconstruímos nossos percursos e evidenciamos o nosso processo de tornar-se.

Tendo como foco entrevistar professores homossexuais, foi preciso estabelecer alguns critérios. Para isto, foi delimitado, então, que os(as) entrevistados(as) seriam professores(as) atuantes nas redes pública e privada de ensino, que estivessem em efetivo exercício, há pelo menos dois anos, que atuassem em diferentes municípios do Vale do Rio dos Sinos, que ocupassem diferentes espaços no contexto educacional, como gestão escolar e assessoria pedagógica, e, por fim, que tivessem diferentes formações (pedagogos/as, professores/as de Língua Portuguesa/Inglesa, Artes, Educação Física, etc.). Após ter encontrado os sujeitos que atendiam a estes critérios, sentiu-se a necessidade de entrevistar futuros(s)-professores(as) e que já estivessem exercendo a docência. Desta forma, foram realizadas mais duas entrevistas (com um professor e uma professora).

Os sujeitos participantes da pesquisa são quatro homens professores gays e uma mulher professora lésbica. A mulher professora lésbica cursa licenciatura em Letras-Português/Inglês, possui 26 anos de idade e atua há quatro anos na rede municipal de São Leopoldo/RS. Atualmente, trabalha com os anos finais do Ensino Fundamental e no Ensino Médio. Um dos homens professores gays é formado em Pedagogia com duas especializações (Coordenação Pedagógica e Docência na Educação Infantil) e tem 44 anos de idade. Atua na rede municipal de Novo Hamburgo/RS há 23 anos. Atualmente, trabalha na Educação Infantil turno integral com turmas de faixa etária de dois anos. 0 segundo, possui formação em Letras Português/Literatura e tem 30 anos de idade. Atua há quatro anos na rede estadual de Esteio/ RS e já trabalhou no ensino privado como professor de pré-vestibular. Atualmente, trabalha com os anos finais do ensino médio. 0 terceiro, possui magistério na modalidade normal, graduado em estudos sociais e em artes visuais e com duas especializações (Cultura Afro-brasileira e Gestão e Supervisão Escolar), 
uma extensão em Atendimento Educacional Especializado e está com 41 anos de idade. Atualmente, é diretor na rede municipal de Canoas/RS e possui 21 anos de exercício da docência. 0 quarto, está cursando Letras/Inglês, atua como professor de Língua Inglesa há sete anos. Tem 30 anos de idade e, atualmente, está atuando em uma escola privada no município de São Leopoldo/RS como professor de idiomas com todas as faixas etárias. As entrevistas foram gravadas em áudio e, posteriormente, transcritas. Os encontros tiveram duração de 35 a 139 minutos.

Cabe destacar, que a primeira ação realizada ao iniciar as entrevistas foi entregar em mãos o Termo de Consentimento Livre e Esclarecido (TCLE), documento no qual apresentamos, brevemente, a pesquisa e seus objetivos, bem como, estabelecemos alguns compromissos com os(as) participantes, sendo um deles, a garantia de preservação da identidade. Por estabelecer um acordo, faremos referência aos(as) entrevistados(as) utilizando nomes fictícios e sugeridos pelos próprios entrevistados.

A seguir, apresentamos um esquema para melhor visualização do material empírico.

Tabela 1 - sistematização do material empírico

\begin{tabular}{lll}
\hline Nome & Tempo em áudio & $\mathbf{N}^{\circ}$ de páginas transcritas \\
\hline Profa. Ju & $01 \mathrm{~h} 2 \mathrm{~min} 09 \mathrm{~s}$ & 23 \\
Ramirez & $38 \mathrm{~min} 10 \mathrm{~s}$ & 10 \\
Caio Fernando & $36 \min 30 \mathrm{~s}$ & 09 \\
Lucas & $35 \mathrm{~min} 02 \mathrm{~s}$ & 12 \\
Rômulo & $01 \mathrm{~h} 38 \mathrm{~min} 14 \mathrm{~s}$ & 30 \\
\hline Total & $3 \mathrm{~h} 69 \mathrm{~min} 5 \mathrm{~s}$ & 84 \\
\hline
\end{tabular}

\section{Fonte: elaborado pelos autores}

Ao analisar-seas entrevistas, foi possivel identificar três categorias de análise que permitem reconstruir as significações que os sujeitos atribuem ao seu processo de profissionalização e profissionalidade, narrando a si mesmo, reconstruindo seus percursos profissionais e evidenciado o processo de tornarse docente. (DAL'IGNA, 2017). Considerando o foco deste trabalho, nos dedicaremos a apresentar duas 
categorias: a produção da docência ex-cêntrica; e a profissionalidade docente homossexual pautada por um ethos inclusivo.

Na primeira categoria analisamos a produção de uma docência ex-cêntrica.

Louro (2003, p. 43), ao analisar o "normal", o "diferente" e o "excêntrico", desde as perspectivas de gênero e sexualidade, mostra que a partir dos anos 1960 tem-se observado um crescimento de movimentos desencadeados por "um conjunto de condições e levado[s] a efeitos por uma série de grupos sociais tradicionalmente submetidos e silenciados".. A autora afirma que estes grupos, ao se manifestarem desde o lugar de onde falavam/falam, - posições desvalorizadas e/ou ignoradas perturbavam/perturbam o "centro" - aquele lugar "materializado pela cultura e pela existência do homem branco ocidental, heterossexual e de classe média" (LOURO, 2003, p. 42) e, que agora, passa(va) a ser contestado e desafiado. Ao manifestarem e problematizarem este centro, não é apenas a constituição dos sujeitos que é posta sob suspeita, mas também

[...] o que passa a ser questionado é toda uma noção de cultura, arte, ética, estética, educação que, associada a esta identidade, vem usufruindo, ao longo dos tempos, de um modo praticamente inabalável, a posição privilegiada em torno da qual tudo mais gravita (LOURO, 2003, p. 42).

Introduzimos esta discussão para mostrar que os sujeitos que não podem ser localizados nesta matriz central e utilizando-se de uma expressão foucaultiana, os que ocupam uma posição de sujeito desviante da norma, são qualificados como "fora do centro", descentrados, ex-cêntricos. Louro (2003, p. 44) nos provoca a refletir que, mesmo concordando que existem muitas formas de viver os gêneros e a sexualidade, ainda assim, a instituição escolar tem orientado suas ações por um padrão, "um modo adequado, legítimo, normal de masculinidade e de feminilidade e uma única forma sadia e moral de sexualidade, a heterossexualidade; afastar-se desse padrão significa buscar o desvio, sair do centro, tornar-se excêntrico".

Segundo Louro (2003, p. 44) somente a posição central é considerada "não-problemática", os sujeitos e as práticas culturais que estão de fora do centro, ou, em outras palavras, nas margens, tornar-se-iam excêntricos e receberiam "as marcas da particularidade, da diversidade e da instabilidade".

A partir das entrevistas com os homens e a mulher, professores homossexuais, pode-se observar uma regularidade em relação as ideias aqui apresentadas. Dos cincos professores entrevistados, dois homens e uma mulher davam-nos indícios de que seus modos de ser/exercer a docência eram/são interpelados por esta posição privilegiada em torno da qual todas as demais posições são avaliadas, classificadas e hierarquizadas. 
Quando questionados(a) se, em algum momento, já haviam enfrentado situações de discriminação, violência de gênero ou LGBT fobia, apenas um professor, acredita não ter sofrido diretamente, mas que, em vários momentos, presenciou estas situações, como podemos ver a seguir.

Lucas: Eu [já vi situações] com colegas onde os alunos trocavam de turma porque o professor era muito espalhafatoso, muito, em outras palavras, porque ele era muito afeminado.

Fonte: Entrevista 4, realizada em 30/04/2018

Profa. Ju: [Eu já lidei com] ex-diretora e ex-coordenadora pedagógica falando mal de mim: "não é uma boa professora porque não é uma boa influência para os alunos; [...] a professora Ju tem um problema, porque ela tem uma namorada, então tu sabe como é que é, né? Tem problemas psicológicos".

\section{Fonte: Entrevista 1, realizada em 17/04/2018}

Ramirez: [...] 0 medo dessa questão da formação de identidade do profissional da educação infantil ou de qualquer outro é que, "ah, ele é gay, o aluno dele vai ser gay, ele é trans o aluno dele vai ser trans [...]".

\section{Fonte: Entrevista 2, realizada em: 26/04/2018}

Nos excertos anteriores, pode-se perceber que o modo de ser, de agir e de estar destes professores, os quais não se enquadram em um modelo de docência considerado a priori como adequado, único e 
legítimo, é percebido como "má influência" para os alunos e alunas. Nas situações narradas pelos professores e pela professora, tanto em um contexto escolar privado quanto em um contexto escolar público, identificamos dificuldades das famílias e dos colegas professores para lidarem com aquilo que foge à regra, à norma.

Aline Teixeira (2015, p. 34-35) afirma que, juntamente com as teóricas feministas e os teóricos queer, é preciso questionar tais discursos

pensando que isso implica a reprodução de uma lógica de normalidade que quem não está dentro dessa norma, que escapa, atravessa essas fronteiras ou até mesmo permanece nas fronteiras precisa ser curado, disciplinado, conduzido para os padrões identificados como os saudáveis.

Algo que é comum entre os relatos dos professores Lucas e Ramirez e da professora Ju, é o fato da profissionalidade ser colocada sob suspeita, ou até mesmo desqualificada, em virtude dos modos como cada um(a) vive seus gêneros e exerce suas sexualidades. Há uma tensão originada pela norma de gênero e sexualidade e, como consequência disto, estes docentes podem ser considerados "ex-cêntricos", como "irreverentes, desrespeitosos, quase iconoclastas por desacatarem normas ou por tornarem ridículos aspectos 'sérios' de nossa cultura" (LOURO, 2003, p. 50), como aqueles que precisam ser conduzidos para os padrões apresentados como mais adequados, sadios, normais.

Rosimeri da Silva (2008), ao discutir em um texto sobre sexualidade a expressão "ponto fora da curva", comumente utilizada pelas ciências exatas e naturais, explica que quando se argumenta contra as atitudes dos homossexuais são frequentes os comentários que associam certas características "anormais" de comportamento sexual à sintomas de desequilíbrio e "doença", como é a situação narrada pela professora Ju anteriormente, ou ainda, pelo professor Rômulo a seguir.

Rômulo: [...] "Ah, mas um homem grande com criança pequena?" então existia até uma questão de assim, "ah, será que não é um pedófilo, será que não quer fazer alguma coisa?". Então, sempre tinha aquela desconfiança, aquele medo, essa questão assim né, e tu acaba sentindo isso, tu sentes, tu luta contra, tu batalha e tu mostra que não é assim, que é um profissional, um professor que acredita na não violência, que acredita no afeto como o carro chefe da educação e das relações [...].

Fonte: Entrevista 5, realizada em: 03/05/2018 
O professor Rômulo mostra que, mesmo após já estar há 23 anos trabalhando na rede de ensino de um município, quando ele muda de escola e inicia em uma nova região, ouve, de algumas famílias, comentários que questionam sua integridade ética, moral, pessoal e profissional como podemos ver na frase "será que é um pedófilo?".

Rosa Silveira (2006, p. 213) ao desenvolver um estudo sobre gênero, sensualidade e paixão em narrativas contemporâneas de contos e crônicas, nos permite refletir sobre os modos de ser docente, atentando para "seus sentimentos, suas atitudes, suas identidades, sua corporeidade, sua sociabilidade, etc.". Segundo a autora, "tal exame procurará perscrutar a dimensão específica do rompimento com uma representação dominante - tradicional - de professora, em especial", a representação "da professora afetuosa, com uma docência tingida pela maternagem ou, ao menos, pelo afeto, movida pela vocação e doação, apresentando-se de forma assexuada, equilibrada, com condutas morais apropriadas". (SILVEIRA, 2006, p. 213).

Outras pesquisas nos ajudam a pensar esta representação da docência como um espaço de/para mulheres; esta visão de um modelo de professora atravessada e constituída pelo afeto, motivada pela vocação e tingida pela maternagem, bem como as implicações de uma docência que é considerada desviante deste modelo. Eduardo Zanette e Maria Cláudia Dal'Igna (2017, p. 121) visando "refletir sobre as relações de gênero que se configuram nos caminhos da profissionalização de homens (futuros) pedagogos" reforçam o que temos demonstrado, de que há um pressuposto de gênero que reduz a masculinidade do homem-professor à sexualidade vista como natural e incontrolável, e que opera na constituição da profissionalidade docente. Ora, se em uma docência heterossexual, o homem-professor é envolvido em diversas estratégias para ser afastado do exercício da docência na educação infantil e tem suas práticas pedagógicas colocadas sob suspeita atuando nos anos iniciais, o mesmo ocorre no exercício da docência homossexual.

Para dar continuidade à análise desta "docência pelo avesso", como nomeia Silveira (2006), vejamos os trechos em destaque: 
Lucas: Eu tinha uma colega que era bissexual e, enfim, ela era toda cheia de tatuagem, de piercing, cabelo colorido, e ela expõe a vida dela total em todas as redes sociais possíveis e ela foi cogitada para ser demitida [...] mas os pais não estavam gostando dela sem nem saber o trabalho dela, sem saber se era uma boa ou não professora, simplesmente, pela aparência dela, por ela ser bissexual, obviamente por ela ser gay. [...]

A minha coordenadora por mais que ela queira manter, ela começou a "catar pelos em ovos" assim, sabe, achar motivos não referentes à sexualidade dela, mas achar coisas: e-mails que ela escrevia errado ou alguma reclamação de alunos sobre minutos a mais ou a menos no intervalo, chegar atrasado, começou a pegar muito no pé dela, porque me parecia que estavam precisando ter material não relacionado à sexualidade dela para poder demiti-la. Eu achei isso o fim da picada [...].

\section{Fonte: Entrevista 4 em: 30/04/2018}

No primeiro trecho da narrativa é possivel perceber, claramente, mais uma vez, a profissionalidade docente sendo colocada sob suspeita, quando ocorre um borramento desta identidade docente tradicionalmente construída, que não se apresenta de forma assexuada, com condutas morais consideradas apropriadas para professores. 0 fato de a professora ser bissexual, ter tatuagens, "expor" sua vida nas redes sociais, fez com que ela, ao não ser considerada uma boa influência para os alunos, fosse demitida, como podemos ver no segundo trecho da narrativa.

Ficam muito evidentes nestes trechos os movimentos e estratégias que ocorrem no interior da instituição escolar para afastar docentes do seu local de trabalho - e, muitas vezes, demitir -, ou para que seus alunos sejam remanejados para outros(as) professores(as), garantindo, assim, o ordenamento de situações que fogem ao controle. É novamente com Louro (2002, p. 51) que entendemos que é preciso

[...] prestar atenção às estratégias públicas e privadas que são postas em ação, cotidianamente, para garantir a estabilidade da identidade 'normal' e de todas as formas culturais a ela associadas; prestar atenção às estratégias que são mobilizadas para marcar as identidades 'diferentes' e aquelas que buscam superar o modelo e a atração que nos provocam as identidades 'excêntricas.'-

Outro movimento que chama atenção está fortemente relacionado com a forma como estes professores e esta professora se comportam no interior das instituições de ensino. Estas docências, 
consideradas "fora do centro", passam a "ser mais aceitas", quando estes docentes são capazes de controlar seus corpos, o que apagaria as marcas de gênero e sexualidade "desviante". Os trechos das entrevistas, a seguir, denotam alguns destes movimentos.

Lucas: Eu acho que nunca passei por isso porque acho que me enquadro naquele grupo de pessoas mais "discretas".

\section{Fonte: entrevista 4, realizada em: 20/04/2018}

Ramirez: [...] Eu sempre quis parecer mais velho para eles [alunos], eu sempre usei barba, eu era bem magrinho, tinha cabelo comprido, queria parecer mais velho usava umas roupas mais sociais, assim, para me impor mais, cheguei a mentir que era casado que tinha filhos, cheguei a passar por um período assim [...].

\section{Fonte: entrevista 2, realizada em: 26/04/2018}

O professor Lucas, ao ser provocado a pensar se já havia sofrido algum tipo de discriminação ou violência de gênero, afirma nunca ter sofrido, pois se enquadra no grupo de pessoas mais "discretas", o que permite com que ele não seja interrogado, questionado sobre sua sexualidade, pois, mesmo sendo um professor homossexual, utiliza estratégias para "camuflar" sua sexualidade, e ser aceito neste ambiente de trabalho.

Há um padrão de masculinidade "aceita" e hegemônica, que, conforme Fernando Seffner (2003, p. 127) é "caracterizado, entre outros, por atributos como violência, força física para exercer a dominação, modos intempestivos de lidar com situações" e que "passa pela definição daquilo que não é masculino, sendo então taxado de feminino ou afeminado". O autor afirma, ainda, nesta direção que "o feminino na mulher é valorizado, embora colocada em situação hierárquica inferior ao masculino do homem. 0 afeminado no homem é desprestigiado, objeto de desprezo". (SEFFNER, 2003, p. 127).- 
O professor Ramirez, da mesma forma que o professor Lucas, "assume" outra identidade sexual para atender à norma, para não ser interrogado sobre sua sexualidade e ser respeitado pelos alunos e, assim, poder exercer a docência.

Ao analisarmos estes silenciamentos, estas formas de violência, pode-se perceber, no entanto, que esta nomeada "docência ex-cêntrica" também cria condições de possibilidade para a constituição de um ethos profissional docente e de uma profissionalidade docente homossexual, nossa segunda categoria de análise.

Quando interrogados(a) se haveria um modo de ser docente homossexual e o que o caracterizaria, dos(as) cinco professores(as) entrevistados(as) três afirmaram existir um modo de ser docente homossexual, pautado nas/pelas questões da inclusão e marcado pelas formas de discriminação e preconceito que sofreram na infância e no exercício da docência. Os outros dois dizem que não há um modo de ser docente propriamente dito, pois o entendem como um processo contínuo, um tornar-se. Quando, no entanto, narram sua prática, sua rotina e relatam seus percursos pessoais e profissionais como docentes, identificamos em nossas análises, certo modo de ser e agir docente homossexual que é interpelado pela diferença.

A diferença referida não é tomada no sentido da educação inclusiva como sinônimo de inclusão educacional das deficiências, mas penso queéuma diferença constituída na/pelasexualidadee constituinte das formas de ser e viver os gêneros e as sexualidades. Percebemos, nos relatos dos professores e da professora, o que descrevem as pesquisadoras Maria Cláudia Dal'Igna e Elí Fabris (2015) ao analisarem a relação de bolsistas do Pibid/Unisinos consigo mesmos. Segundo elas, nesta relação "pode-se perceber como cada sujeito constitui-se nesse processo de formação por meio das relações sobre si mesmo e a forma como cada sujeito age e reflete diante das situações" (DAL'IGNA; FABRIS, 2015, p. 84).

A seguir, apresentamos dois excertos que nos permitem fazer estas reflexões.

Profa. Ju: Primeiramente, eu não sei se existe um modo de ser professor. Eu acho que cada professor tem seu modo de ser, mas eu não tenho como negar que sim, o fato de eu ser lésbica, como ser humana eu tenho uma visão diferente do que é preconceito, por exemplo. [...] eu acho que a gente acaba sendo mais combatível às questões de preconceito pelo fato da gente sofrer preconceito, então esse background que a gente passou vem junto, tem uma forma. A nossa forma de ver o preconceito é diferente pelo fato de sofrer ele.

Fonte: entrevista 1, realizada em: 17/04/2018 
Rômulo: [...] eu tenho um olhar diferenciado, existe uma sensibilidade maior, um entendimento maior porque eu já passei por esse processo de discriminação e de diferenciação e de preconceito, então se a criança que sofre preconceito em função da cor da pele, em função da família dela, em função do meu olhar vai ser diferente, pois já passei por isso, mesmo que seja pela questão de gênero e sexualidade, mas eu passei por preconceitos, passei por discriminação. Meu olhar é diferente daquele que nunca passou e nunca teve experiências dessa forma [...].

\section{Fonte: entrevista 5, realizada em: 03/05/2018}

Os excertos acima são representativos de uma recorrência evidenciada na pesquisa. Percebemos o quanto a constituição docente destes professores e desta professora é interpelado pela diferença. Percebemos, também, a constituição de um ethos profissional inclusivo, que tem relação com o que descrevem Dal'Igna e Fabris (2015). Segundo elas, o ethos seria "certo modo de ser e agir, resultado de processos pelos quais cada um aprende a ver a si mesmo, a refletir sobre suas próprias ações, a operar transformações em si mesmo". (DAL'IGNA; FABRIS, 2015, p. 78). As autoras vão nos fazer pensar que esse ethos pode se constituir como uma outra via de (auto)formação, na medida que é necessária uma escolha, um pertencimento, uma postura crítica como princípio de/para transformação.

A partir das análises identificamos que a profissionalidade dos homens professores gays e da mulher professora lésbica, sujeitos da pesquisa, é pautada não apenas por um modo de ser docente que é "excêntrico", mas por certo ethos profissional, certo modo de ser e agir que é inclusivo. Compreendemos, neste momento, que este ethos pode contribuir para a problematização e a desconstrução de relações de poder de gênero e de sexualidade naturalizadas e/ou socialmente sancionadas e, também, para diminuir e/ou modificar determinadas formas de discriminação e de violência.

Percebemos que, ao enfrentarem situações de discriminação na infância e no exercício da docência, os professores e a professora se constituem de outras formas e assumem uma postura profissional atravessada e constituída pelos discursos das diferenças de gênero e sexualidade. Vejamos um exemplo disso: 
Profa. Ju: [...] o fato de eu ser lésbica, me dá uma noção de o quanto que a gente pode oprimir um aluno; então, na minha sala de aula eu tento que seja um ambiente mais livre de preconceito, mais seguro possível para o meu aluno e não algo que vá reproduzir preconceitos que vá derrubar ele pra baixo [...].

\section{Fonte: entrevista 1, realizada em: 17/04/2018}

Esta docência interpelada pela diferença nos parece ter uma forte relação com o que descreve Luciana Loponte (2006, p. 13) ao olhar para uma docência artista, pois segundo Loponte, esta docência seria "uma docência que se coloca em cena para si mesma", que "não ambiciona ser um modelo a ser repetido, ou uma receita para a produção de uma "boa" docência". Nas palavras de Loponte (2006, p. 13) "o que importa aqui é o que essa docência artista pode fazer pensar ou, o que, desde essa experiência, a partir dela, ou contra ela, podemos pensar sobre nós mesmos e sobre a docência".

É este o movimento que estes docentes homossexuais mobilizam ao exercer sua docência, um pensar sobre si e sobre os outros, para, então, pensar os modos de ser e agir como docentes. Concordando com Loponte (2006, p. 8), entendemos que

A relação com o outro não se estabelece pela simples obediência, pela sujeição e submissão às verdades verticais, o que, por outro lado, não quer dizer também um falso democratismo dialógico. A relação com o outro está baseada na invenção, criação estética de si mesmo. Ao me olhar no outro, ao me reconhecer na diferença do outro, me esculpo de modo distinto. 
O professo Rômulo, descrevendo este modo de ser docente homossexual, corrobora o que Loponte (2006) diz no excerto acima:

Rômulo: [...] tem uma sensibilidade diferente aí, nessa questão docente, existe uma sensibilidade diferente do professor hétero e do professor homossexual, vejo por mim, falo por mim, não pelos outros, se eu servir pra pesquisa aí tu já tem alguma coisa, por mim eu digo que tem [...].

\section{Fonte: entrevista 5, realizada em: 03/05/2018}

Loponte (2006) ao descrever do que se trata sua pesquisa, nos faz pensar na possibilidade de uma formação docente para além das "competências", nos provocando, inspirada por Foucault (1998) em uma etopoética docente. Segundo ela

A estética da existência ou o cuidado consigo mesmo apontam para a invenção de novas formas de atuar, outras maneiras de constituir o êthos do sujeito. Esta é necessariamente uma ação compartilhada, que se dá em relação com os outros. (LOPONTE, 2006, p. 4).

Em outro estudo, Loponte $(2008$, p. 5) nos provoca a pensar, olhando para a estética da formação docente, a partir de Foucault e Nietzsche, que

[...] há inúmeras possibilidades de ser docente. Uma docência que se faz "artista" pode ser aquela que assume o seu trabalho como um processo de ir e vir, de rascunhar, rabiscar, voltar a desenhar-se. Um trabalho sobre si mesmo que não se faz sozinho. As relações intersubjetivas são fundamentais para a formação docente. Não há estética de si mesmo na solidão.

Para pensar em uma docência homossexual interpelada pela diferença faz-se necessário, entendêla não somente como um processo de ir e vir, mas, parafraseando Loponte (2008), como um trabalho sobre si mesmo, numa dimensão ética e estética, que não se faz sozinho e que é resultado das relações intersubjetivas e, muitas vezes, vivenciado pela solidão e pelo sofrimento.

O professor Lucas, ao descrever esta docência homossexual, ao mesmo tempo em que a entende como sendo "mais trabalhosa", evidencia este sentimento de solidão ao dizer que, muitas vezes, não 
pode socializar sua vida vivida fora do ambiente escolar, pois sente uma tensão referente à norma e pensa que, ao falar sobre o que fez com o namorado no final de semana, por exemplo, causaria no mínimo um estranhamento. Analisemos o excerto abaixo.

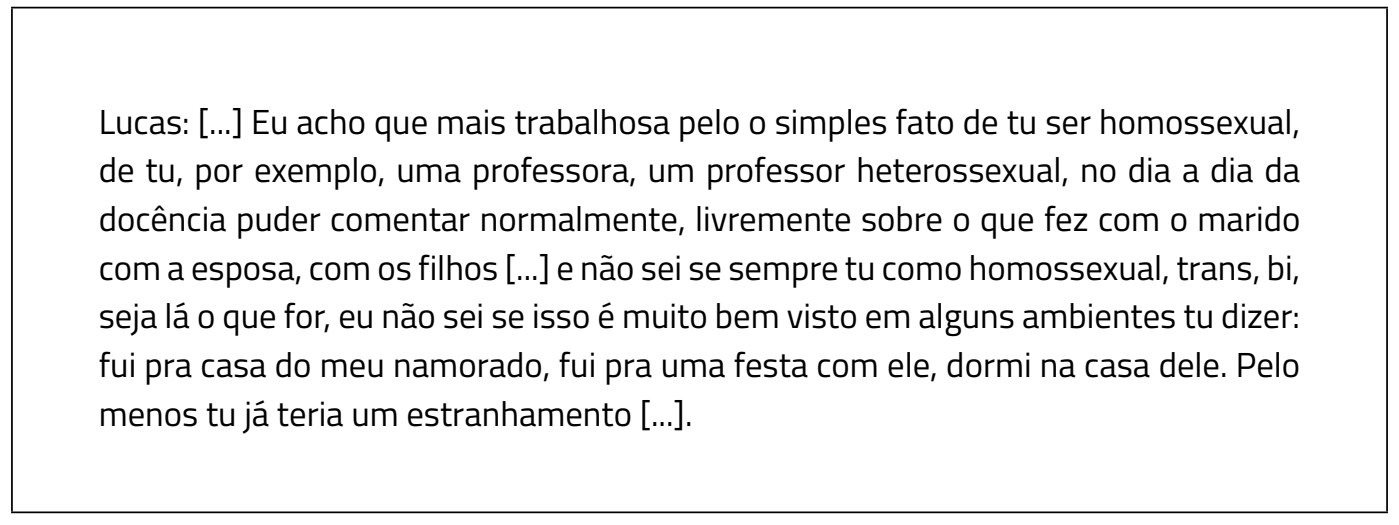

\section{Fonte: entrevista 4, realizada em: 30/04/2018}

A partir das análises desenvolvidas foi possível perceber que, mesmo que estes professores e esta professora ainda lutem por defender sua profissionalidade, para serem reconhecidos e respeitados por seus modos de exercer a docência e suas formas de viver, seus gêneros e suas sexualidades, mesmo que ainda vivam entre o medo por não se enquadrarem em uma docência tida como referência, mobilizam uma docência homossexual que é mais sensivel às questões de discriminação e preconceito que outros seres humanos podem experimentar. Entendemos que pode estar se constituindo aí, um ethos profissional inclusivo, muito semelhante com os modos de ser docente artista.

Sendo assim, ao mostrar como gênero e sexualidade atravessam e dimensionam a docência homossexual, mais especificamente a profissionalidade, e mesmo com todas as implicações e complexidades que estas narrativas mobilizam, percebeu-se a possibilidade de deslocamento de uma docência considerada ex-cêntrica para uma docência interpelada pelos discursos inclusivos que criam condições para pensarmos a constituição de um ethos profissional inclusivo. Este ethos profissional inclusivo se forma na medida em que, ao (re)significarem as experiências - sejam elas consideradas positivas ou negativas -, vividas na infância e no exercício da docência, estes professores e esta professora, ao se relacionarem consigo mesmo e com os outros, ao se olharem no outro e se reconhecerem na diferença do outro, mobilizam outras formas de ser e exercer a docência. 
Pensamos, ainda, que esta pesquisa pode contribuir para nos fazer refletir como docentes e formadores de futuros/as docentes sobre as formas como nós nos tornamos mulheres e homens, professores e professoras de determinados tipos, e, assim, contribuir para diminuir e/ou modificar, de forma importante, o exercício destes tipos de violência.

Outras questões foram suscitadas pelo material e, muitas delas, produzidas pelas complexas narrativas dos professores e da professora participantes da pesquisa e pelas inúmeras potencialidades analíticas, muitas das quais não tivemos condições de explorar neste momento, mas que, certamente, poderão desdobrar-se em pesquisas futuras, mesmo que não possamos "prever os rumos do que vem [...] cada vez que um novo estado se estabelece, imediatamente começa o movimento de se desestabelecer e dar lugar a outro que vem" (VILLELA, 2013, p. 170-171).

Sendo assim, acreditamos que, ao nos colocarmos em movimento, mesmo não sabendo os rumos do que vem é necessário para desestabelecer àquilo que pensamos saber e, mais do que isto, é possibilitar que outras coisas possam ser ditas e permitir que possamos nos (re)constituir de outras formas.

\section{REFERÊNCIAS}

ANDRADE, Sandra dos Santos. A entrevista narrativa ressificada nas pesquisas educacionais pósestruturalista. In: MEYER, Dagmar Estermann; PARAíSO, Marlucy Alves (Org). Metodologia de pesquisas pós-críticas em educação. Belo Horizonte: Mazza, 2014. p. 175-196.

DAL'IGNA, Maria Cláudia; FABRIS, Elí Henn. Constituição de um ethos de formação no Pibid/Unisinos: processos de subjetivação na iniciação à docência. Educação Unisinos, São Leopoldo, v. 19, n. 1, p. 7787, 2015.

DAL'IGNA, Maria Cláudia. A produção de sentidos sobre afeto, amor e cuidado na formação inicial docente sob a perspectiva de gênero (2017-2021). São Leopoldo: Programa de Pós-Graduação em Educação, Universidade do Vale do Rio dos Sinos. 2017. [Projeto de Pesquisa].

FOUCAULT, Michel. O sujeito e o poder. In: DREYFUS, Hubert L. Michel Foucault: uma trajetória filosófica (para além do estruturalismo e da hermenêutica). Rio de Janeiro: Forense Universitária, 1995. P. 231249. 
FOUCAULT, Michel. História da sexualidade I: a vontade do saber. Rio de Janeiro: Paz e Terra, 2017.

GIMENO SACRISTÁN, José. Consciência e acção sobre a prática como libertação profissional dos professores. In: NÓVOA, António (Org.). Profissão professor. Porto: Porto Editora, 1995. p. 63-92.

LOPONTE, Luciana Gruppelli. Docência artista: arte, gênero e ético-estética docente. Educação em Revista, Belo Horizonte, UFMG, v. 43, n. 43, p. 35-55, 2006.

LOPONTE, Luciana Gruppelli. Arte e estética da docência: conversas com Nietzsche e Foucault. Educação e Arte, Santa Catariana, UDESC, n. 16. ANPED/SUL, 2008.

LOURO, Guacira Lopes. Gênero, sexualidade e educação: uma perspectiva pós-estruturalista. Petrópolis: Vozes, 2011.

LOURO, Guacira Lopes. Pedagogias da sexualidade. In: . (Org.). 0 corpo educado. Belo Horizonte: Autêntica, 2014.

LOURO, Guacira Lopes. Currículo, gênero e sexualidade - o "normal", o "diferente" e o "excêntrico". In: LOURO, Guacira L.; NECKEL, Jane F.; GOELLER, Silvana V. (Org.). Corpo, gênero e sexualidade: um debate contemporâneo. Petrópolis: Vozes, 2011.

LOURO, Guacira Lopes. Um corpo estranho: ensaios sobre sexualidade e Teoria Queer. Belo Horizonte: Autêntica, 2004.

MEYER, Dagmar E. E. Gênero e educação: teoria e política. In: LOURO, Guacira L.; NECKEL, Jane F.; GOELLER, Silvana V. (Org.). Corpo, gênero e sexualidade: um debate contemporâneo. Petrópolis: Vozes, 2011.

MONTEIRO, Agostinho Reis. Profissão docente: profissionalidade e autorregulação. São Paulo: Cortez, 2015.

NICHOLSON, Linda. Interpretando o gênero. Revista Estudos Feministas, Santa Catarina, UFSC, v. 8, n. 2, 2000.

PEREIRA, Marcos Villela. Traços de fundamentalismo pedagógico na formação de professores. Revista Iberoamericana de Educación, v. 47, n. 5, p. 1-13, 2008.

PIMENTA, Sema Garrido. (Org.). Formação de Professores: identidade e saberes da docência. In: PIMENTA, Selma Garrido. Saberes pedagógicos e atividade docente. São Paulo: Cortez, 2008. p. 15-34. 
SEFFNER, Fernando. Derivas da masculinidade: representação, identidade e diferença no âmbito da masculinidade bissexual. 2003. Tese (Doutorado em Educação) - Programa de Pós-Graduação em Educação, Universidade Federal do Rio Grande do Sul, 2003.

SILVA, Rosimeri Aquino da. O ponto fora da curva. In: MEYER, Dagmar; SOARES, R. Corpo, Gênero e sexualidade. Porto Alegre: Mediação, 2008. p. 85-94.

SILVA, Jonathan Vicente da. Gênero, sexualidade e profissionalidade: uma análise das narrativas de docentes homossexuais. 2018. Trabalho de Conclusão de Curso (Licenciado em Pedagogia) - Curso de Pedagogia, Universidade do Vale do Rio dos Sinos (UNISINOS), São Leopoldo, 2018.

SILVEIRA, Rosa M. Hessel da. Professoras pelo avesso: gênero, sexualidade e paixão em narrativas contemporâneas. In: COSTA, Marisa Vorraber. (Org). 0 magistério na política cultural, Canoas, 1. ed. v. 1, p. 211-234, ULBRA, 2006.

SCOTT, Joan. Gênero: uma categoria útil de análise histórica. Educação e Realidade, Porto Alegre, v. 20, n. 2, jul./dez., 1995. p. 71-99.

TEIXEIRA, Aline. As "verdades" sobre gênero e sexualidade na formação docente: incursões no Programa Institucional de Bolsas de Iniciação à Docência - Pedagogia/Unisinos. 2015. Trabalho de Conclusão de Curso (Licenciado em Pedagogia) - Curso de Pedagogia, Universidade do Vale do Rio dos Sinos (UNISINOS), São Leopoldo, 2015.

ZANETTE, Jaime Eduardo. Homens (futuros) pedagogos? Relações de gênero nos caminhos de profissionalização. 2014. Trabalho de Conclusão de Curso (Licenciado em Pedagogia) - Curso de Pedagogia, Universidade do Vale do Rio dos Sinos (UNISINOS), São Leopoldo, 2014.

ZANETTE, Jaime Eduardo; DAL'IGNA, Maria Cláudia. "Ser homem" e "ser pedagogo": relações de gênero nos caminhos da profissionalização. Textura, Canoas, v. 20, n. 43, p. 121-150, mai./ago. 2018.

WEEKS, Jeffrey. O corpo e a sexualidade. In: LOURO, Guacira Lopes. (Org.). 0 corpo educado. Belo Horizonte: Autêntica, 2015. p. 35-82. 